\title{
Implicações epistemológicas da pesquisa sobre novas práticas jornalísticas: por onde começar?
}

\section{Epistemological implications for research in new journalistic practices: where to start?}

\author{
Myrian Regina Del Vecchio de Lima \\ Jornalista. Doutora em Meio Ambiente e Desenvolvimento pela Universidade Federal do Paraná (UFPR). Mestre em \\ Comunicação pela Universidade Metodista de São Paulo. Professora do Departamento de Comunicação Social da UFPR. \\ $<$ myriandel@gmail.com>
}

\section{Kati Eliane Caetano}

Doutora em Letras pela USP. Pós-doutorado em Semiótica pela Université de Liège e Groupe de Recherches Sémiotiques da EHESS, de Paris, França, e pós-doutorado em Ciências da Linguagem, na École Normale Supérieure de Lyon e Université de Paris VII, Paris. Professora e pesquisadora do PPG em Comunicação e Linguagens da Universidade Tuiuti do Paraná (UTP). <katicaetano@hotmail.com>

\section{RESUMO}

Este texto pergunta por onde começar uma pesquisa que busque definir as implicações epistemológicas sobre novas práticas jornalísticas, levando-se em conta que há quase duas década pesquisadores têm se dedicado a compreender os limites e características do jornalismo contemporâneo que responde por várias denominações, a maioria relacionada com os processos tecnológicos de digitalização e convergência de formatos/suportes. Ao buscar subsídios para a indagação inicial, o texto parte do mapeamento de trabalhos relacionados à temática, apresentados em cinco eventos da Associação Brasileira de Pesquisadores em Jornalismo (SBPJor). A pesquisa levantou até 2014 inúmeras denominações que designam as novas práticas; os resultados iniciais sinalizam para novas indagações no âmbito da discussão epistemológica sobre o fazer jornalístico contemporâneo, caracterizado pela hibridação de ambientes e fluxos informativos online e offline, dilatação de fontes e autorias e multiplicidade de dispositivos.

Palavras-chave: Espistemologia do jornalismo. SBPJor. Novas práticas jornalísticas.

\section{ABSTRACT}

This paper makes questions about how to begin a research that seeks to define the epistemological implications of new journalistic practices, taking into account that, since almost two decades, there are researchers that have been dedicated to understand the limits and characteristics of contemporary journalism, that answer by several denominations, the most of that related to the technological processes of scan and convergence of formats and media. For getting subsidies for the initial question, we mapped the works related to the theme, presented in five events of the Brazilian Journalism Researchers Association (SBPJor). The research raised until 2014 numerous appellations that designate the new practices; the initial results indicate new questions about the epistemological discussion about doing contemporary journalistic, characterized by hybridization and informational flows and environments both online and offline, dilation of authorships and multiplicity of sources and devices.

Keywords: Epistemology of journalism. Brazilian Journalism Researchers Association. New journalistic practices. 


\section{Introdução}

A profunda transformação pela qual passa o jornalismo mundial é causada, predominantemente, - e aqui não há nenhum tipo de intenção de ligar este fato ao determinismo tecnológico - pela convergência dos conteúdos noticiosos produzidos e distribuídos nas novas plataformas digitais. Como afirmam Ruellan e Adghirni (2009, p.8), "as novas tecnologias não são um motor de transformações por si só, mas um novo espaço e, eventualmente, um acelerador, destas transformações". À semelhança de qualquer outro contexto de crise, daí decorrem fragilidades e rupturas, às vezes "destempos" e "desordenamentos", como diz Gómez (2006); bem como surgem mutações e metamorfoses, assim como novas possibilidades, que irão conviver com antigas formas e essencialidades inerentes a um campo, visão ou modelo.

Todas estas mudanças e permanências vêm sendo observadas, nos últimos anos, com relação ao campo jornalístico, o que leva a se descrever e refletir sobre a formação de novos objetos e de novas práticas e rotinas produtivas, aqui denominadas sob o termo "Novas Práticas Jornalísticas" (NPJs).

Compreendem-se as NPJs, de forma ampla, como o conjunto das recentes alterações incluídas nas rotinas de produção e distribuição diária de conteúdos do jornalismo profissional (um campo agora exposto à intensa interação com novos sujeitos produtores de mensagens públicas que se inserem em espaços antes exclusivos dos especialistas), a partir de um cenário marcado pela inclusão das tecnologias digitais e online de comunicação.

Para ser possível olhar as práticas de formas indiferenciadas, utilizamos o entendimento de Ruellan e Adghirni (2009, p.12) quando afirmam estar convencidos de que "o jornalismo é uma prática social de produção discursiva antes de ser uma profissão", criando para tanto uma definição básica de jornalismo como "uma prática sociodiscursiva" que coloca "em interação três instâncias salientadas pela sociologia profissional: as fontes, as práticas, os públicos" (Ruellan e Adghirni, 2009, p.12). Os autores avançam ao afirmar ainda que "o jornalismo é definido além da relação estável entre atores especiais e atividades distintas que fundam o mito da autonomia e da independência jornalística" (Ruellan e Adghirni, 2009, p.12) e afirmam que as fontes, as práticas e os públicos são instâncias "consideradas como pólos ou papeis podendo serem investidos por atores diferentes ou idênticos" (Ruellan e Adghirni, 2009, p.12). Esta concepção permite que se possa "lançar um novo olhar sobre as práticas indiferenciadas ou, ao contrário, integrar a formação discursiva, que uma visão 
exclusivamente normativa rejeita como não jornalística" (Ruellan e Adghirni, 2009, p.12).

Marcondes Filho (2009) observa que o campo do jornalismo passou por duas grandes revoluções históricas, ambas decorrentes de novas tecnologias (evidentemente permeadas por outras pequenas revoluções): a criação da rotativa, em 1850, que, de certa forma, permitiu que os jornais se tornassem empresas lucrativas, "fábricas de notícia", numa produção que se pode classificar como "fordista", com implicações editoriais complexas; e a informatização ocorrida, em diferentes momentos em cada país, mas de forma geral, a partir da década de 1970, quando os computadores iniciaram a substituição das máquinas de escrever e aceleraram a produção jornalística com inserção de outra nova lógica produtiva. O conjunto de alterações que marca profundamente o campo jornalístico atual tem origem na apropriação social e profissional de todas as inovações tecnológicas relativas à comunicação, em um cenário de globalização acelerada, que se inicia a partir dos anos de 1990. Ao se referir à entrada da Internet no circuito profissional do jornalismo, e ao citar também Marcondes Filho, Borelli observa que

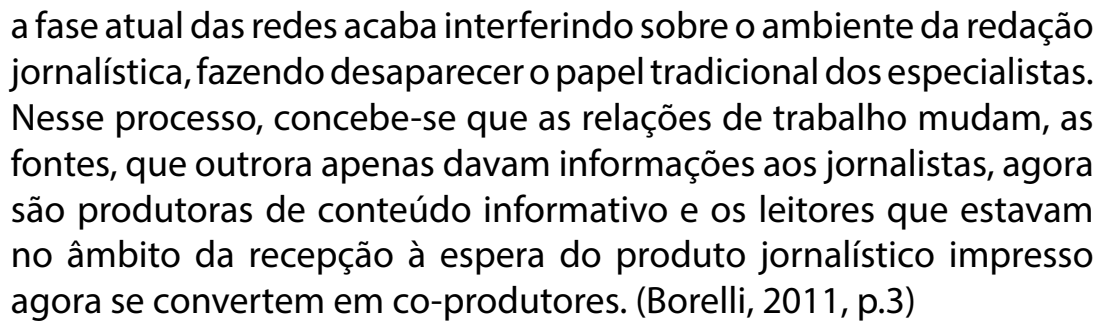

Este é apenas um dos aspectos diretamente ligado à produção de conteúdos informativos que caracterizam as novas práticas jornalísticas, decorrentes da rápida apropriação das tecnologias de comunicação pelo campo. Recorde-se, como acentua Borelli (2011, p. 2), que por ser uma prática social específica, o jornalismo vai lidar com interferências "dos múltiplos sentidos produzidos pelas diferentes mídias", em especial o campo vai receber a interferência da internet "como mídia dominante"; assim, neste contexto de intensa midiatização1 da sociedade e do campo jornalístico em particular, o

1 Para Borelli (2011, p. 1-2), "a midiatização se constitui num complexo processo em que os dispositivos midiáticos agem sobre outros campos sociais, estruturando e engendrando suas ações por meio de operações tecno-simbólicas". Para a autora, no processo, um dispositivo técnico e simbólico passa a interferir e dar forma "aos contratos produzidos no âmbito da produção com objetivo de atingir a 
papel do especialista, antes quase sacralizado, passa a ser relativizado perante as múltiplas possibilidades de interação entre produção e recepção. Observase o que alguns pesquisadores chamaram de "embaralhamento das fronteiras" jornalísticas (estabelecidas entre estratégias, práticas, identidades, produtos e enunciados) e a constatação de que, enfim, não havia mais fronteiras:

Estávamos diante de um jornalismo híbrido, sem contornos nítidos, onde as fronteiras tradicionais eram transgredidas e apropriadas por outros campos da comunicação. Não apenas o jornalismo, mas todas a práticas da mediação e da midiatização, bem como a produção cultural, o papel dos atores, das organizações públicas e privadas, dos receptores, dos públicos, estavam "contaminadas" pela confusão das fronteiras tradicionais. (Ruellan e Adghirni, 2009, p.9)

Modifica-se fortemente, neste contexto, a organização produtiva e de distribuição de conteúdos (textos e imagens noticiosas) veiculados nas mais diferentes mídias articuladas no espaço global/local - tanto nas chamadas hegemônicas, representadas pelas grandes corporações internacionais e nacionais, pioneiras no processo e distribuidoras mundiais/nacionais de conteúdo, quanto nos veículos de imprensa regionais/locais; possibilitou-se, além do mais, o surgimento de uma quantidade inédita de veículos digitais de produção individual ou de grupos sociais/coletivos independentes, que introduzem alternatividades ao campo hegemônico das grandes mídias. No jornalismo brasileiro, o processo teve início com a informatização das redações, ainda nos anos 1990, seguida pelo início do uso das potencialidades e possibilidades de práticas on-line, permitidas pela chegada da Internet ao país.

No âmbito das novas formas de disponibilizar conteúdos jornalísticos, assinale-se, em 1995, o Jornal do Brasil, do Rio de Janeiro, como o primeiro veículo de imprensa nacional a ter uma versão on-line (que inicialmente apenas reproduzia a versão impressa)2; em 1996, é lançado o Brasil Online, primeiro jornal em tempo real, em língua portuguesa, da América Latina, conhecido hoje na rede como Folha Online. Quatro anos depois, o provedor de acesso à Internet Grátis (IG) coloca na rede o Último Segundo, um jornal digital produzido

recepção." (Borelli, 2011, p.1) Ao se aceitar este conceito de midiatização, pode-se depreender que as mídias deixam de ser apenas canais de transmissão, mas se tornam dispositivos. Neste sentido, Borelli recorre a Mouillaud (1997) ao firmar que as mídias "possuem uma forma e um conteúdo que podem pré-determinar os sentidos através dos modos de apresentação daquilo que dizem" (Borelli, 2011, p.2). 2 O Jornal do Brasil (JB), um dos mais antigos do País - é publicado há 122 anos - deixou de circular impresso em papel em setembro de 2010, quando passou a ter uma versão $100 \%$ online. 
especialmente para a Internet brasileira. Assim, da reprodução do jornal impresso tal e qual na Internet, passa-se a exigir, gradativamente, uma produção específica para o modelo on-line, que demandou, para sua elaboração e edição, novas equipes e produção diferenciada que atendesse às características das plataformas on-line. Registre-se nesse sentido um dos textos pioneiros no Brasil sobre esse aspecto de fases de desenvolvimento de jornalismo na web, de autoria de Luciana Mielniczuk (2003), "Sistematizando alguns conhecimentos sobre o jornalismo na web"3.

$\mathrm{Na}$ atualidade, praticamente todos os grandes jornais brasileiros possuem suas versões on-line; e há jornais apenas on-line, como o já citado Jornal do Brasil e o jornal O Estado do Paraná, em Curitiba, PR; e o mais importante para o recorte aqui apresentado: as rotinas de práticas jornalísticas, em veículos impressos, eletrônicos tradicionais (rádio e TV) e digitais on-line (sites, blogs e produção jornalística em mídias sociais) apresentam, em especial a partir do final dos anos 1990/início dos anos 2000, com diferenciais em relação a cada veículo, grandes alterações nas formas de produção da notícia (seleção, apuração/ captação, elaboração e edição), bem como nas suas formas de disseminação (publicação em várias plataformas, simultaneamente, e de forma convergente, e compartilhamentos). Ou seja, efetivamente, entra-se em um período de intensa digitalização do jornalismo.

Em trabalho abrangente que verificou o estado da arte em jornalismo no Brasil, no período de 2000 a 2010, Strelow (2011) apontou, entre outras considerações:

\footnotetext{
- O crescimento dos estudos a respeito do jornalismo digital, como previsto pelos pesquisadores da área (Wainberg e Pereira, 1999), transformou-se em realidade; [...]

- As rotinas produtivas em jornalismo constituem a base de um número representativo de trabalhos, em uma tentativa de fazer dialogar academia e mercado, de produzir ciência olhando para a realidade; [...]

- O crescimento dos estudos sobre jornalismo digital e transformações no jornalismo contemporâneo está relacionado aos trabalhos inseridos no campo teórico da convergência midiática e das novas mídias; [...]

- O interesse dos pesquisadores pelo meio jornal para escolha do objeto empírico continua surpreendendo; [...]
}

3 O texto citado faz parte da coletânea "Modelos de Jornalismo Digital" (2003), organizada por Elias Machado e Marcos Palácio, então pesquisadores do também grupo pioneiro no país na área, o GJOL (Grupo de Jornalismo Online), da Universidade Federal da Bahia, que reúne dez artigos de pesquisadores do grupo. 
- A tendência é que despontem ainda mais os estudos voltados às tecnologias do jornalismo, em especial os relacionados à convergência tecnológica; [...]

- Embora tenha crescido o interesse pelo estudo das rotinas produtivas, a pesquisa em jornalismo no Brasil segue com escassa relação com o mercado de trabalho. Intensificar essa relação para fazer valer a prática científica é um dos principais desafios os quais precisamos nos impor [...] (Strelow, 2011, p. 86-88).

O que interessa no âmbito do eixo de investigação na pesquisa internacional (Novas Práticas Jornalísticas: o impacto das novas tecnologias de informação no jornalismo) onde este texto se insere (aquele epistemológico, que procura delimitar um marco teórico para o conceito de jornalismo no século $\mathrm{XXI})^{4}$, não é analisar as implicações destas alterações no processo de produção da notícia para os jornalistas profissionais, em termos de aspectos trabalhistas e sindicais envolvidos, ou as novas questões éticas profissionais daí decorrentes, temas fundamentais de serem analisados e muito instigantes.

Interessa no recorte mais amplo dessa pesquisa perceber como essas novas exigências de produção alteraram as práticas produtivas, ou seja, como as NPJs foram instauradas e se apresentam cada vez mais necessárias nas redações, a partir de demandas crescentes de público e mercado. Não apenas pelo fato de os veículos jornalísticos estarem praticamente todos on-line e atuando de forma midiática convergente, mas também pelo fato de que outras modalidades de suporte técnico, como os dispositivos móveis de comunicação (celulares e tablets), foram sendo apropriados pela sociedade, ganhando espaço entre os consumidores de informação, que passaram a ser altamente interativos e também a se estabelecerem, muitas vezes, como partícipes da produção da informação, em termos de envio de textos e imagens que se inserem na produção jornalística profissional.

\footnotetext{
4 "Novas Práticas Jornalísticas: o impacto das novas tecnologias de informação no jornalismo", pesquisa internacional, cujas bases foram definidas em junho de 2014, durante o ISeminário Acadêmico-Científico, do Convênio de Cooperação França-Brasil-Líbano, realizado em Lyon (Université Lyon II-Lumiére), quando também se estabeleceram os primeiros passos de uma pesquisa sobre o impacto das Novas Tecnologias da Informação no campo jornalístico a ser realizada por equipes dos países participantes do acordo: Brasil, França e Líbano. A proposta aprovada em Lyon foi a de encaminhar uma pesquisa científica com três eixos de investigação: a) um epistemológico, que procure delimitar um marco teórico para o conceito de jornalismo no século XXI; b) um cartográfico, que pretende mapear o que está sendo feito nos países conveniados sob a denominação de jornalismo, e, finalmente, c) a análise do impacto dessas novas tecnologias nas redações, a partir da análise de um veículo único, presente nos três países, no caso, o jornal online The Huffington Post. Tem ainda o propósito de promover uma discussão sobre as demarcações e características de uma atividade profissional na era do acesso ilimitado às mais variadas tecnologias de produção e difusão de informação.
} 
Em um recorte bem mais restrito, definido para este texto de acordo com o eixo um da pesquisa internacional acima citada, pergunta-se por onde começar uma pesquisa que busque definir, inicialmente, as implicações epistemológicas sobre novas práticas jornalísticas, levando-se em conta que há pelo menos mais de uma década pesquisadores brasileiros têm se dedicado a compreender, por meio de sistematizações e categorizações, os limites e características de jornalismo contemporâneo que responde por variadas denominações.

E foi por aí exatamente que decidimos começar, antes mesmo de se delinear um mapeamento sobre as NPJs no país, um dos objetivos da pesquisa internacional citada. Ou seja, em um primeiro momento, perguntamos: quais as denominações pelas quais se rotulam essas práticas jornalísticas intensamente mediadas pela tecnologia digital, multiplataforma, com emissores-receptores que se confundem e com produção e distribuição de conteúdos em convergência?

O objetivo inicial então é simples e bem delimitado: levantar as várias denominações pelas quais se apelidam estas novas práticas produzidas pelos/ para os cibermeios, referindo-se aos respectivos conceitos e críticas, a partir dos autores que têm se dedicado nos últimos anos ao seu estudo. Assim, Zamith (2011) admite com relação à maioria dos estudiosos da área que "depois de algumas hesitações iniciais, é hoje assumido consensualmente que as características distintivas da Internet justificam a existência de um novo tipo de jornalismo." (Zamith, 2011, p.23). E, nós diríamos, de "novos tipos de jornalismo", mas todos eles com essencialidades que permitem manter o campo do ponto de vista científico e profissional.

Podemos então verificar, em um primeiro momento, os conceitos estabelecidos para jornalismo colaborativo (também conhecido como jornalismo cidadão, jornalismo democrático ou jornalismo open-source, quando cidadãos comuns, sem formação profissional específica, participam da produção jornalística, por meio dos recursos tecnológicos disponíveis); e de jornalismo transmídia ${ }^{5}$, quando o mesmo tipo de produção jornalística é

\footnotetext{
${ }^{5} \mathrm{Na}$ área de jornalismo, a narrativa transmídia é considerada tendência ainda não aplicada, com efeito, na prática, de acordo com Denis Renó (2012), que aponta que este tipo de narrativa é utilizada há tempos no cinema e na publicidade, tendo como característica estrutural uma história compartilhada em fragmentos, utilizando múltiplas plataformas: mas é sobretudo "um conteúdo expandido, que circula pelas redes sociais, sofre um processo viral e conta com uma produção também para dispositivos móveis". (Disponível em: <http://jornalismo-e-redes-moveis.ubi.pt/2012/11/jornalismo-transmidianao-e-jornalismo-cross-media)/>). Renó alerta que transmídia não é cross-media, "uma notícia contada a partir de diversas histórias (independentes), em distintos meios (e linguagens), que, em conjunto, oferecem uma nova história passível de comentários e circulação por redes sociais e em dispositivos
} 
adaptado, simultaneamente, para mídias diferentes, atendendo muito bem à forte demanda das diferentes plataformas móveis (embora possa se manifestar em diversas mídias tradicionais como livros, por exemplo), o que implica práticas de produção, edição e distribuição diferenciadas.

Mas, verificamos também várias outras denominações que foram encontradas por meio de um procedimento específico de pesquisa quantitativa6, do tipo estado da arte, no maior evento que reúne pesquisadores de jornalismo no país: o da SBPJOR (Associação Brasileira de Pesquisadores em Jornalismo), no período 2009-20137.

\section{A temática das NPJs nos eventos anuais da SBPJor}

Em estágio ainda inicial da pesquisa (2014), os trabalhos publicados nos anais online dos eventos realizados pela Intercom (que não constam da análise deste trabalho) e pela SBPJor, por cinco anos, foram distribuídas em planilha do programa Excel, organizados nas seguintes categorias: subevento, título do trabalho, autor(es) e suas qualificações, origem geográfica/institucional do trabalho, resumos, palavras-chave e referências bibliográficas utilizadas.

No mapeamento de trabalhos da SBPJor são alcançados dois diferentes âmbitos de pesquisa: aquelas realizadas nos cursos de graduação em jornalismo, por meio de projetos de Iniciação Científica e dos Trabalhos de Conclusão de Curso (TCCs), verificados por meio dos Anais dos três eventos consecutivos do II Encontro de Jovens Pesquisadores em Jornalismo (2011-2013), modalidade criada a partir de 2011, para estimular a pesquisa entre os jovens estudantes de jornalismo; e no nível das pesquisas de mestrado e doutorado, por meio dos Anais dos cinco eventos consecutivos (2009-2013) do Encontro Nacional de Pesquisadores em Jornalismo.

De acordo com o site da instituição (<http://www.sbpjor.org.br $>$ ), ao longo dos últimos cinco anos, o encontro anual da SBPJor consolidou-se como o principal fórum brasileiro para a discussão acadêmica do jornalismo como

móveis". (Renó, disponível em: <http://jornalismo-e-redes-moveis.ubi.pt/2012/11/jornalismotransmidia-nao-e-jornalismo-cross-media)/>).

6 A coleta de dados nos anais de cinco anos de eventos da SBPJor e a organização dos dados em gráficos foi realizada pelos estudantes de jornalismo da UFPR, Luiza Pollo Mazurek e Victor Parolin Schnekenberg, que estiveram no segundo semestre de 2014 em Mobilidade Acadêmica na Université Lyon2-Lumière, na França, com bolsa UFPR.

7 A pesquisa internacional, mais ampla, busca, em um dos seus objetivos, verificar como os pesquisadores brasileiros vêm abordando as NPJs em trabalhos apresentados em grandes eventos da área realizados no país, assim como em suas produções publicadas. 
campo científico. Metade dos mais de 300 associados atuais da organização são doutores, vinculados a mais de cem instituições brasileiras, dos Estados Unidos, França e Portugal. O corpus empírico mapeado, no âmbito da SBPJor, refere-se, aos eventos realizados, em ordem cronológica, nas seguintes cidades brasileiras: 7. Encontro, em São Paulo, SP (Universidade de São Paulo-USP), 2009; $8^{\circ}$. Encontro, em São Luís/MA (Universidade Federal do Maranhão - UFMA), 2010; $9^{\circ}$. Encontro, no Rio de Janeiro, RJ (Universidade Federal do Rio de Janeiro UFRJ), em 2011; 10. Encontro, em Curitiba/PR (Pontifícia Universidade Católica do Paraná - PUCPR), em 2012; e 11․ Encontro em Brasília/DF (Universidade de Brasília - UnB), em 2013. Os Encontros de Pesquisadores da SBPJor se organizam a partir de Comunicações Livres e Comunicações Coordenadas (encontro de pesquisadores organizados por Grupos de Pesquisa em torno de um tema, com mesas previamente aprovadas).

As totalizações são as seguintes, relativas aos cinco anos de evento: de um total de 1.130 trabalhos publicados, 236 estavam relacionados às NPJs, o que corresponde a $20,9 \%$ do total. Do total de trabalhos, 656 eram comunicações livres (58\%), com 114 delas relativas às NPJs (17,4\% das comunicações livres), 305 trabalhos em mesas coordenadas foram publicados, com 95 destes constituindo temáticas de NPJs (31,14\% dos trabalhos das mesas coordenadas). Os 169 trabalhos restantes foram relativos ao encontro de jovens pesquisadores, sendo 27 deles sobre NPJs (16\%).

Figura 1: SBPJor: total de trabalhos entre 2009-2013 e número de trabalhos sobre novas práticas jornalísticas no mesmo período.

SBPJor - Total entre 2009 e 2013

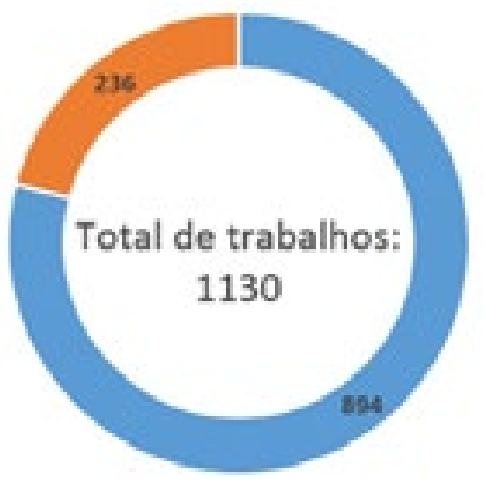

- Trabahos com outras tematicas

- Trata hos com a temitica de novas praticas jomalistican

Fonte: $<$ http://soac.bce.unb.br/index.php/ENPJor/JPJor/schedConf/presentations $>$. Acesso em: 29 jun. 2015. Autores: DEL VECCHIO DE LIMA. MAZURECK e PAROLIN, 2014. 
Fig.02- SBPJor: trabalhos apresentados entre 2009-2013 por eventos do seminário nacional, com destaque para os trabalhos sobre novas práticas jornalísticas com relação ao demais temas.

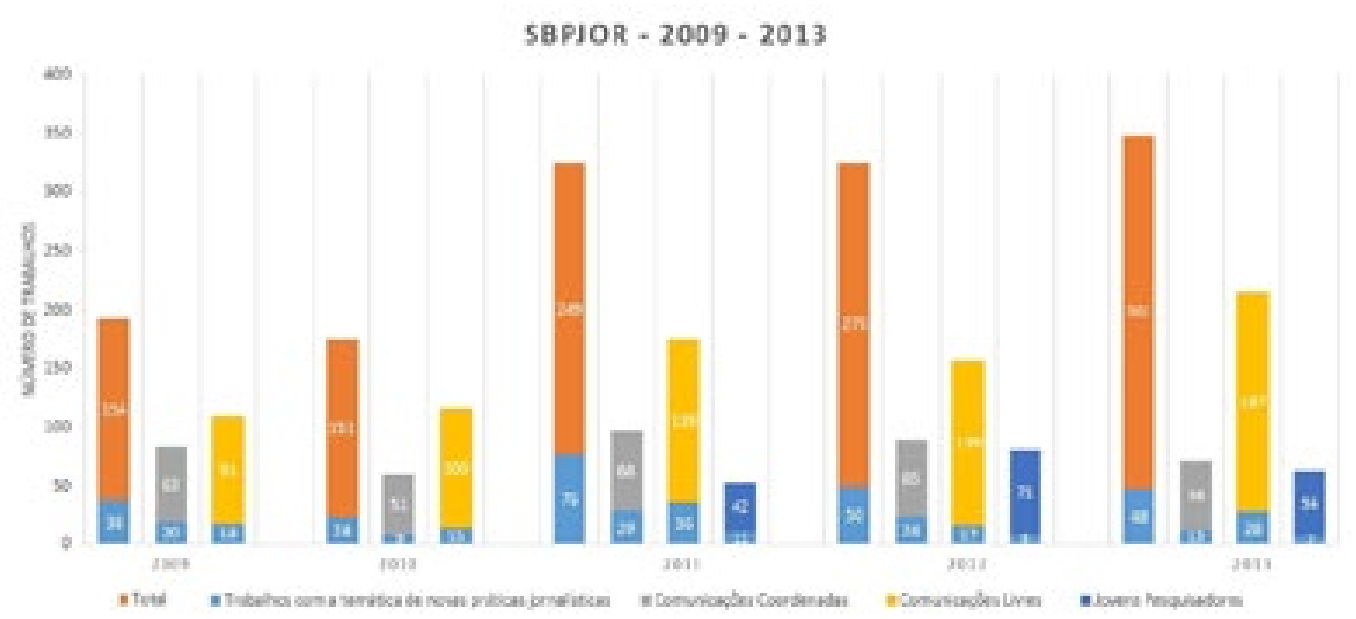

Fonte: <http://soac.bce.unb.br/index.php/ENPJor/JPJor/schedConf/presentations > Acesso em: 29 jun. 2015. Autores: DEL VECCHIO DE LIMA. MAZURECK e PAROLIN, 2014.

Deixamos de lado, neste texto, nos trabalhos sobre NPJs, os resultados encontrados em cinco anos de SBPJor para as categorias "origens geográfica e institucional" dos trabalhos e "autores e suas qualificações", já devidamente compiladas e analisadas, mas que não constam deste paper. Apresentamos uma breve análise sobre a categoria "referências bibliográficas" encontradas, para a seguir nos concentrarmos na categoria "palavras-chave", ponto central de interesse deste artigo.

Com relação aos autores referidos bibliograficamente no conjunto de trabalhos sobre NPJs nos cinco anos de eventos da SBPjor, apreciados até o momento (dezembro de 2015), foi realizada a compilação dos autores mais citados, a partir da observação visual dos 35 mais recorrentes. Entre estes, observam-se evidentemente a predominância de autores de língua portuguesa, brasileiros e portugueses (como Canavilhas, Fidalgo, Alsina e Traquina); seguido pelos autores de língua inglesa, com destaque para Jenkins, que tem trabalhado com o tema da "convergência", uma das palavras-chave mais citadas nos trabalhos examinados, após o termo genérico jornalismo; há poucos autores de língua espanhola e francesa (possivelmente pela falta de mais obras traduzidas no Brasil), apesar das importantes contribuições de Ruellan, Le Cam e outros autores em grupo de pesquisa que interagiu nos últimos anos com pesquisadores da Universidade de Brasília.

Seguem-se os doze autores mais citados no universo de trabalhos em exame: 1) Marcos PALACIOS (111); 2) Elias MACHADO (93); 3) Henry JENKINS 
(67); 4) Raquel RECUERO (64); 5) Manuel CASTELLS (55); 6) Ramón SALAVERRÍA (49); 7) André LEMOS (46); 8) Luciana MIELNICZUK, (45); 9) Alex PRIMO (42); 10) Nelson TRAQUINA (41); 11) Antonio FIDALGO (33); 12) Javier Diaz NOCI e Mark DEUZE (32 cada). Observe-se nestes destaques os fundadores do primeiro grupo de pesquisa de jornalismo online do Brasil, Palacios e Machado, liderando a lista - com obra, pioneira, de 2003, "Modelos de Jornalismo Digital", por eles organizada, na qual definiram e diferenciaram os conceitos até hoje utilizados de webjornalismo, jornalismo online, jornalismo de internet e jornalismo digital. Jenkins aparece em terceiro lugar como autor da obra "A cultura da convergência", sendo a convergência a segunda palavra chave mais citada no conjunto dos trabalhos; os autores brasileiros Rachel Recuero, André Lemos, Luciana Mielnivzuk e Alex Primo têm sido utilizados por cursos de graduação e pós-graduação intensamente no país na última década; Castells continua aparecendo significativamente anos após o impacto de suas obras "Sociedade em Rede" "A Galáxia da Internet", consideradas por muitos com acentuado viés de determinismo tecnológico; Traquina surpreende ao aparecer nesta lista, pois é autor mais ligado a uma teoria do jornalismo em geral não especificamente sobre suas novas manifestações; e o português Fidalgo tem sido um dos autores de seu país, ao lado de Canavilhas, considerado referência na área do jornalismo e suas práticas digitais.

\section{Os diferentes tipos de jornalismo que emergem das palavras-chave}

Do total de 236 artigos articulados às NPJs em exame nos cinco anos de eventos da SBPJOR foram identificadas quase três centenas de palavraschave (291) relacionadas com as variadas denominações dadas ao (s) tipo (s) de jornalismo analisado (os) pelos trabalhos científicos apresentados.

Ao levar em conta palavras-chave identificadoras das ênfases nos trabalhos científicos, Meditsch e Segala (2004) lembram que, com relação à colocação do termo "jornalismo", entre elas, a iniciativa das sociedades científicas acompanhou a evolução dos números registrados pelo diretório dos grupos de pesquisa do Conselho Nacional de Desenvolvimento Científico e Tecnológico (CNPq), principal órgão de apoio à pesquisa cientifica no Brasil. No primeiro censo realizado por esses autores, em 1993, nenhum grupo colocava o jornalismo entre suas palavras-chave. No levantamento de 2002, já apareciam 15. Em junho de 2003, o total registrado no diretório do CNPq havia passado para 47 grupos. Na base corrente de 2005 chega a 68 o número de grupos que registram o jornalismo como objeto de estudo. 
Dessa forma, o total de trabalhos sobre NPJs mapeados em cinco anos de SBPJor, obviamente o termo jornalismo reitera a área, aparecendo 73 vezes; mas, do uso do termo unificador do campo de pesquisa seguemse para aqueles diversificadores, que vão evidenciar as permanentes e novas formas de jornalismo que aparecem sob as mais variadas denominações (que têm sido apontadas, internacionalmente, como mutações, transformações e metamorfoses do campo), o que sinaliza para a exigência posterior de se examinar as conceituações, pelo menos das mais utilizadas: assim aparecem 1) jornalismo digital (24 vezes), webjornalismo/jornalismo na web (20 vezes), jornalismo online (15), ciberjornalismo (14), jornalismo móvel (cinco), jornalismo colaborativo (quatro), jornalismo alternativo e jornalismo participativo (três vezes cada); aparecem ainda jornalismo de fonte aberta (open source), jornalismo cidadão, jornalismo em rede, jornalismo na internet, jornalismo líquido, jornalismo imersivo, jornalismo computacional, jornalismo emergente, jornalismo em base de dados, jornalismo convergente (denominações que aparecem uma vez cada). Como curiosidade, aparece até mesmo a expressão pouco usual, mas bem descritiva como prática, de jornalismo sentado.

Observe-se que as tipologias se dão pela referência ao suporte ou local de circulação, como em webjornalismo (19), mas também pela referência às novas formas de inserção do usuário/cidadão na produção jornalística profissional, como em jornalismo colaborativo. Há ainda uma tipologia relativa às características de flexibilidade e diluição da informação por múltiplos canais, bem como de sua ubiquidade, como no caso de jornalismo líquido ou convergente. Perceba-se que são quase vinte classificações de "novas" formas de jornalismo em um passeio pelo espaço de cinco anos de apenas um evento da área, o que aponta, sem dúvida, para uma dinâmica intensa no interior do campo 8 .

As divisões por área ou por gênero, tradicionais do jornalismo, mantêmse, por meio das palavras-chave como telejornalismo/jornalismo televisivo (oito), jornalismo de revista (seis), fotojornalismo, jornalismo impresso e radiojornalismo (quatro vezes cada), jornalismo cultural (duas) e jornalismo internacional, jornalismo de agência, jornalismo científico, jornalismo esportivo (uma vez cada).

Há ainda as palavras-chave que se referem diretamente a veículos de comunicação especificamente enfocados: jornais Zero Hora, Folha de S.Paulo,

8 Com base em pesquisas, Danah Boyd, doutora pela Universidade de Berkeley, (citada por Pisani; Piotet, 2010, p.298), afirma que, no campo das criações e estudos da web, "a cada cinco anos, é necessário algo novo, uma nova expressão". O jornalismo apenas atesta esse fenômeno em um setor específico das trocas simbólicas 
Rádio Independência AM etc., com pouco mais de uma dezena de ocorrências como palavras-chave; as mídias sociais digitais específicas, como Facebook (cinco vezes) e Twitter (13), com um número surpreendentemente baixo de palavraschave; além dos meios em si, como televisão, rádio, internet, fotografia, redes sociais, sites informativos, networking, audiovisual, blogosfera. Evidentemente, aqui e no conjunto de todas as palavras-chave a serem aferidas quando da totalidade da pesquisa, será necessária a ajuda de um software específico para sua análise quantitativa, com posterior análise qualitativa.

Destacam-se ainda palavras-chave relativas a teorias próprias do jornalismo, como valores notícia/noticiabilidade (nove vezes), newsmaking (quatro) e rotinas produtivas (cinco); características da Internet, como interatividade (16), multimidialidade/intermedialidade (sete); aos novos formatos possíveis, como blogs jornalísticos/microblogs (oito); novos suportes, como dispositivos móveis/mídias móveis (cinco), tablets (dez), smartphones (quatro) e TV digital (cinco); Base de dados/jornalismo em base de dados (11).

Enfim, aparecem assim as seis palavras-chave mais utilizadas: 1) Jornalismo (73 vezes), 2) Convergência/convergência midiática-jornalística (34); 3) Internet (25); 4) Jornalismo Digital (24); 5) Webjornalismo (19) e Redes Sociais (19); 6) Jornalismo On-line (15). Do conjunto, merece ser comentado o número de vezes em que aparece o termo convergência midiática-jornalística, o que indica o grande interesse despertado por esta característica das mídias tecnológicas, que vem imprimindo novas práticas no circuito de produção da notícia, em especial, nas suas formas de distribuição/circulação.

Diante deste panorama inicial bastante amplo, apesar de fechado em cinco anos de um único evento acadêmico nacional, e concentrado exclusivamente em trabalhos específicos que estivessem relacionados a NPJs, definimos como primeiro passo da pesquisa epistemológica em início de desenvolvimento, verificar e entender os conceitos e críticas ligados às diferentes denominações aqui encontradas.

\section{Considerações finais}

Do ponto de vista dos conteúdos discutidos, as reflexões e os debates em torno do papel do jornalista na sociedade contemporânea, em espaços híbridos on-line e off-line, têm enfatizado o descentramento de sua ação no âmbito dos agendamentos e controle de pauta. Ao contrário, no contexto do jornalismo móvel e de características multiplataformas, em ambientes colaborativos propiciados pela web 2.0, fazer jornalismo implica não apenas dotar-se de 
múltiplas competências, mas, sobretudo, agir como mediador de um processo contínuo de produção de informações e/ou de remissões. A mediação, nesse caso, tem traços bem demarcados nos fluxos informacionais porque pressupõe capturar fatos/notícias em uma corrente complexa de dados, adequá-los a diferentes formatos e gerenciar o processo de circulação ininterruptamente. Ou seja, integrar-se a um circuito de trocas em que o próprio jornalista é, ao mesmo tempo, produtor, receptor e comentador. O processo é contínuo, mesmo para a mídia impressa, que ainda se mantém no ritmo da produção para o dia seguinte, mas que deve incorporar em sua pauta as atualizações de sites e redes de notícias e suas contínuas transformações. Trata-se, em suma, de processos à deriva, em permanente construção e desconstrução, nos quais a questão do erro passa a ser incorporada como fato rotineiro, quase naturalizado, desprezando, em muitas ocorrências denunciadas pelas redes sociais, qualquer justificativa ou explicação.

O ambiente favorece, ainda, uma produção paralela de falsas notícias, apresentadas como fatos reais, que visam a questionar a suposta objetividade e neutralidade da imprensa, assim como o caráter de responsabilidade social que Ihe é tradicionalmente atribuído.

Nesse cenário, a figura do jornalista passa a ser revista, em especial a partir do momento em que se legitima sua profissão sem escolarização específica, independente de certificações institucionais, com a dispensa do diploma. A própria imprensa, na tentativa de acompanhar os novos tempos, abre espaço às múltiplas vozes da sociedade, muitas vezes sob a forma de um gerenciamento controlado pela liberação de espaços próprios a tais sujeitos, ou convocando a sua participação a partir de motes centrados na ideia de um jornalismo cidadão.

Entretanto, na palestra de abertura do evento de 2013 da SBPJor, a pesquisadora belga Florence Le Cam acentuou uma mudança nesta flexão, ao lembrar que não é aceitável se deter apenas nas metamorfoses do jornalismo atual, mas é preciso fazer reflexões também sobre o que ele apresenta de permanente e de constante, pontos que vão garantir sua legitimidade e credibilidade, características conquistadas ao longo de sua história como campo de relevância social, ainda que de forma tardia.

Apesar de todas estas mudanças, a figura do jornalista está fortemente presente tanto de fato como de direito no imaginário social, porque dele depende ainda a organização da noticiabilidade em espaços midiáticos legitimados, mesmo que tal fenômeno esteja articulado ao rumo dos acontecimentos e dos fluxos fora dos ambientes mainstream. Na verdade, não há mais como se opor à grande mídia e à produção em redes, porque se configura um quadro de 
citações recíprocas, homologadoras ou polêmicas, na base de um sistema de citações.

É nessa conjuntura que se coloca a questão de partida para o debate sobre o que é ser jornalista hoje e o que é fazer jornalismo na cultura contemporânea, dentro do espírito da interatividade, da produção colaborativa e da multiplicidade de vozes, produzindo e discutindo informação, visibilizada no próprio espaço midiático.

Com relação às palavras-chave encontradas neste passeio por cinco anos de trabalho apresentados em grande evento nacional de Jornalismo, termos que cruzam o universo conceitual do debate acadêmico, indaga-se, ainda: que pressupostos subjazem a tal diversificação/fragmentação do campo, em que medida refletem pontos de vista sobre as práticas discursivas constituídas pelo jornalismo, ou representam, de fato, novas tendências nos modos de construir informação?

Daí a importância de, na sequência, parar para examinar estas palavraschave, que não guardam em si inocência nem descuido (apenas ocasionalmente), mas, sim, sinalizam para estas novas tendências já apontadas e reforçam as fragmentações do campo, instigando novos olhares/leituras epistemológicas.

\section{Referências}

BLOG JORNALISMO E REDES MÓVEIS. Jornalismo transmídia não é jornalismo crossmedia. Disponível em: <http://jornalismo-e-redes-moveis.ubi.pt/2012/11/ jornalismo-transmidia-nao-e-jornalismo-cross-media)/>. Acesso em: 26 ago. 2014.

BORELLI, Viviane. O processo de midiatização do jornalismo: desafios e perspectivas da prática laboratorial. IN: IV Sipecom (Seminário Internacional de Pesquisas em Comunicação, Estratégias e Identidades Midiáticas), 2011, Santa Maria, RS. Anais do IV Sipecom. Santa Maria: UFSM, 2011. Disponível em: < http://coral. ufsm.br/sipecom/anais/artigos/gt3.html>. Acesso em: 15 maio 2014.

GÓMEZ Guillermo Orozco. Comunicação social e mudança tecnológica: um cenário de múltiplos desordenamentos. In:MORAES, Dênis de (Org.).Sociedade midiatizada. Rio de Janeiro: Mauad, 2006. MARCONDES FILHO, Ciro. Ser Jornalista: o desafio das tecnologias e o fim das ilusões. São Paulo: Paulus, 2009. 
MEDITSCH, E. \& SEGALA, M. A pesquisa brasileira em jornalismo apresentada na SBPJor. Comunicação ao II Congresso Nacional de Pesquisadores em Jornalismo (SBPJor). Salvador, novembro de 2004.

MIELNICZUK, Luciana. Sistematizando alguns conhecimentos sobre o jornalismo na web. In: MACHADO, Elias; PALACIOS, Marcos (Org.). Modelos de jornalismo digital. Salvador: Calandra, 2003. p. 37-54.

PISANI, Francis; PIOTET, Dominique. Como a web transforma o mundo: a alquimia das multidões. São Paulo: Senac, 2010.

RENÓ, Denis Porto; VIVAR, Jesús M. Flores. Periodismo transmedia: reflexiones y técnicas para el ciberperiodista desde los laboratorios de medios interactivos. Madrid: Editorial Fragua, 2012.

RUELLAN, Denis; ADGHIRNI, Zélia Leal. O Jornalismo como invenção permanente: novas práticas, novos atores. Disponível em: <http://www.intercom.org.br/ papers/nacionais/2009/resumos/R4-1559-1.pdf>. Acesso em: 14 maio 2014.

SBPJOR. Portal da Associação Brasileira dos Pesquisadores em Jornalismo. Disponível em: <http://www.sbpjor.org.br>. Acesso em: 29 jun. 2015.

STRELOW, Aline. O estado da arte da pesquisa em jornalismo no Brasil: 2000 a 2010. Intexto. Porto Alegre, UFRGS, v.02, n²5, p. 67-90, dez. 2011.

ZAMITH, Fernando. A Contextualização no ciberjornalismo. Tese. (Doutorado em Comunicação). Universidade do Porto, Portugal, 2011. Disponível em: <http:// repositorio-aberto.up.pt/bitstream/10216/57280/2/zamith000148443.pdf $>$. Acesso em: 26 ago. 2014.

Recebido em 06 de fevereiro de 2015.

Aceito em 19 de maio de 2015.

Endereço das Autoras:

Myrian Regina Del Vecchio de Lima <myriandel@gmail.com>

Universidade Federal do Paraná - UFPR

Programa de Pós-Graduação em Comunicação - PPGCom

Rua Bom Jesus, 650, térreo - Bairro Juvevê

CEP 80035-010 - Curitiba/PR.

Kati Eliane Caetano <katicaetano@hotmail.com>

Universidade Tuiuti do Paraná - UTP

Programa de Pós-Graduação em Comunicação e Linguagens - PPGCom

Rua Sydnei Antônio Rangel Santos, 238 - Bairro Santo Inácio

CEP 82010-330 - Curitiba/PR. 